\title{
Anterograde and retrograde amnesia of place discrimination in retrosplenial cortex and hippocampal lesioned rats
}

\author{
Asahi Haijima and Yukio Ichitani ${ }^{1}$ \\ Institute of Psychology and Behavioral Neuroscience, University of Tsukuba, Tsukuba, Ibaraki 305-8577, Japan
}

\begin{abstract}
Retrograde and anterograde amnesic effects of excitotoxic lesions of the rat retrosplenial cortex (RS) and hippocampus (HPC) were investigated. To test retrograde amnesia, rats were trained with two-arm place discrimination in a radial maze $4 \mathrm{wk}$ and $1 \mathrm{~d}$ before surgery with a different arm pair, respectively. In the retention test $1 \mathrm{wk}$ after surgery, both lesion groups showed temporally ungraded retrograde amnesia. To test anterograde amnesia, animals were trained after surgery to discriminate three arm pairs successively within a day, and then after interposition of 1- to 4-wk intervals, one of these pairs, respectively, was tested for retention. RS-lesioned rats could acquire these pairs of place discriminations rapidly but showed a retention interval-dependent impairment in the retention test. Conversely, HPC-lesioned rats took more sessions to acquire these pairs than did the control group, and their retention was $\sim 70 \%$ of correct performance regardless of retention interval. Results suggest that RS and HPC have different roles in spatial memory and that RS is important for remote memory process.
\end{abstract}

Recent studies indicate that the retrosplenial cortex (RS) may contribute to spatial learning and memory in humans (Valenstein et al. 1987; Maguire 2001) and rodents (Sutherland et al. 1988; Vann and Aggleton 2002, 2004). In addition, the RS might cooperate with the hippocampus (HPC) to engage in spatial learning and memory, since the RS has dense reciprocal neural connections with the hippocampal formation (Vogt 1986; Wyss and van Goren 1992; Burwell and Amaral 1998), which is important for learning and memory, and both RS and HPC contain neurons with spatial firing properties such as "head direction cells" (Chen et al. 1994; Cho and Sharp 2001) and "place cells" (O'Keefe and Nadel 1978). Furthermore, the neural activity of RS affects the hippocampal spatial coding (Cooper and Mizumori 2001) and the hippocampal theta wave activity (Destrade and Ott 1982; Vanderwolf et al. 1985), which is related to learning and memory (Pan and McNaughton 1997). Moreover, fornix transection or HPC lesions caused a reduction of c-Fos expression in RS during radial maze performance (Vann et al. 2000; Albasser et al. 2007).

It has been considered that memory function depends on an interaction between HPC and the neocortical areas (e.g., Squire 1992; Eichenbaum et al. 1994; Nadel and Moscovitch 1997). Most of these perspectives assumed that long-term memory is stored in the neocortex. Thus, the RS might be one of the candidate brain regions that form a network with hippocampal formation in memory function, especially in long-term memory processing. However, there were few lesion studies that demonstrated the role of the RS in spatial memory processes and that directly compared the effects of lesions of the RS and HPC. Thus, it remains unclear whether the RS is important for spatial longterm memory and whether the roles of the RS and HPC in spatial memory could be clearly differentiated.

Here we compared retrograde and anterograde amnesic effects of RS and HPC lesions on two-arm place discrimination in a radial maze. We made dorsal HPC lesions since dorsal HPC has been reported more important for spatial memory than is ventral

'Corresponding author.

E-mail y-ichit@human.tsukuba.ac.jp; fax 81-29-853-6094.

Article is online at http://www.learnmem.org/cgi/doi/10.1101//m.862308.
HPC (e.g., Pothuizen et al. 2004). To test retrograde amnesia (Experiment 1), animals were trained at different time periods prior to surgery, and a retention test was conducted after surgery. Anterograde amnesia (Experiment 2) was assessed both by postsurgical acquisition of the two-arm place discrimination and by retention test of the task after various retention intervals.

Male Wistar-Imamichi rats $(n=22$ and 23 in Experiment 1 and 2, respectively), 3-4 mo old (mean, $318 \mathrm{~g}$ ), were maintained at $80 \%-85 \%$ of their free feeding weight and housed individually and kept on a 12-h light-dark cycle. All behavioral testing was conducted during the light cycle (08:00-20:00 h). Animal experiments were approved by the University of Tsukuba Committee on Animal Research. All efforts were made to minimize the number of animals used and their suffering.

An elevated eight-arm radial maze made of gray polyvinyl chloride was used. It consisted of an octagonal central platform (35 $\mathrm{cm}$ in diameter) and eight arms $(60 \times 12 \mathrm{~cm})$ radiating from the central platform. The side wall of each arm was $4 \mathrm{~cm}$ high. A food well ( $3 \mathrm{~cm}$ in diameter and $1 \mathrm{~cm}$ deep) for three food pellets (45 mg each, Bio-Serv Inc.) as a reward was placed $1 \mathrm{~cm}$ from the end of each arm. A transparent guillotine door that controlled the rats' access to the central platform was placed between each arm and the central platform. There were many kinds of extramaze cues (e.g., blackboard, shelf, desk) around the maze in the experiment room $(2.4 \times 2.4 \mathrm{~m})$.

For the place discrimination task, pairs of four adjacent arms out of eight arms were used (named P1-P4 in a trained order). These arm pairs differed among subjects. One arm of each pair was always baited as a positive arm ( $\mathrm{S}+$ ), whereas the other was not baited throughout experiment as a negative arm $(\mathrm{S}-)$. The position of the $S+$ arm (i.e., left or right) was counterbalanced across arm pairs and lesion groups.

Each trial began by opening both doors of the arm pair after a confinement of the subject into the central platform for $20 \mathrm{sec}$. If the rat ran down to the $\mathrm{S}+\mathrm{arm}$, it could get the reward (correct response). If the rat ran down to an arm end of the arm pair, the rat was picked up and immediately returned to the central platform. After a 20 -sec confinement (i.e., intertrial interval), the same pair of doors were reopened for the next trial. By using this 
length of confinement time, we could prevent animals from developing a bias such that when the door was opened, their orientation was not random, since animals did not remain stationary for $20 \mathrm{sec}$ and moved around in the central platform. Thus, animals could not use a response/cue strategy, and we could test spatial memory in this task. Each session consisted of 12 consecutive trials, and the intersession interval was 10-20 min. The animals received continuous training in a day until they reached the learning criterion of 11 or more correct responses in one session. In the retention test, only one session under the same procedure was conducted.

In Experiment 1 (Fig. 1A), each rat was trained with P1 and $\mathrm{P} 2$ in $2 \mathrm{~d}$. These two pairs were used for training of the task itself, and they were not used for retention test. One week after P2 acquisition, the animals were trained with P3 and P4 for acquisition. P3 was trained $4 \mathrm{wk}$ before surgery, and $\mathrm{P} 4$ was $1 \mathrm{~d}$ before surgery. On the next day of $\mathrm{P} 4$ acquisition, the animals were randomly assigned to RS $(n=8)$, HPC $(n=7)$, or sham-operated control (Cont; $n=7$ ) groups on the basis of sessions to criterion in P3 and P4. After 1-wk recovery period from surgery, they were given a retention test (12 trials) of $\mathrm{P} 3$ and $\mathrm{P} 4$ within a day. The order of the P3 and P4 test was counterbalanced.

In Experiment 2 (Fig. 1B), the rats were trained with P1 within a day. P1 was used for training of the task itself and was not used for retention test. On the next day of P1 acquisition, the animals were randomly assigned to RS $(n=8)$, HPC $(n=7)$, or Cont $(n=8)$ groups on the basis of sessions to criterion in P1. After 1-wk recovery period from surgery, they were given acquisition training of P2-P4 within a day. After acquisition of these pairs, 1-, 2-, or 4-wk intervals were interposed, and one of these pairs was tested for retention (12 trials), respectively. The assignment of which interval was interposed for P2-P4 was counterbalanced.

Surgery was conducted under sodium pentobarbital anesthesia $(40 \mathrm{mg} / \mathrm{kg}$, i.p.) using a stereotaxic instrument (David Kopf). The excitotoxic lesions were produced by $\mathrm{N}$-methyl-D-

A: Experiment 1: Test of retrograde amnesia

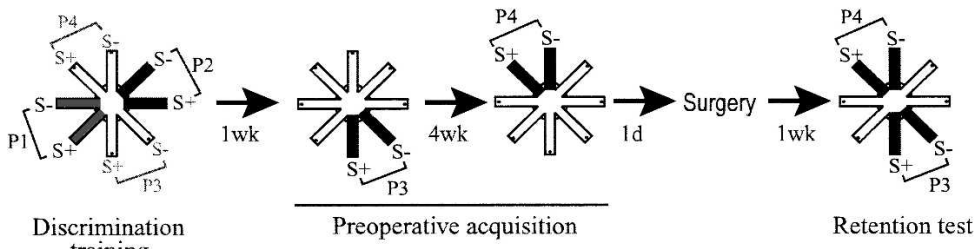
training

B: Experiment 2: Test of anterograde amnesia

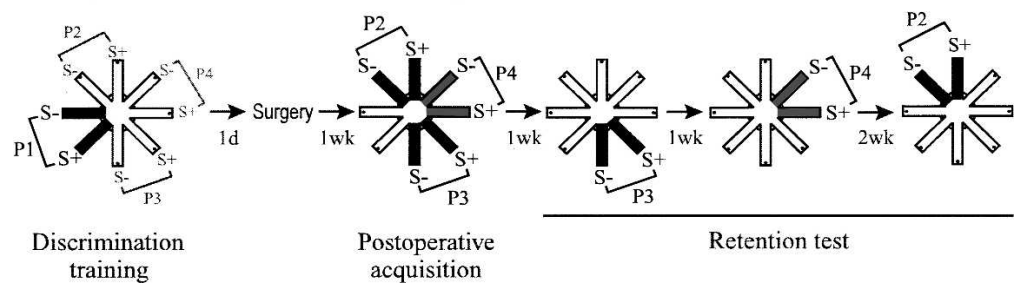

Figure 1. Two-arm place discrimination task in a radial maze. $S+$ and $S-$ represent always-baited and always-unbaited arms, respectively. P1-P4 denote the order of acquisition in place discrimination training. (A) A typical procedure in Experiment 1. Subjects were preliminarily trained with P1 and P2 in discrimination training in $2 \mathrm{~d}$. One week after P2 acquisition, rats were trained with P3 and P4, 4 wk or $1 \mathrm{~d}$ before surgery, respectively. One week after surgery, they were given retention tests for $\mathrm{P} 3$ and P4 within a day. The arm pairs and S+ arms were different among subjects. (B) A typical procedure in Experiment 2. Rats were trained with P1 on the previous day of surgery. After 1 wk recovery period, the animals were given acquisition training for P2 to P4 within a day. After acquisition of these pairs, a 1-, $2-$, or 4-wk interval was interposed, and one of these pairs was tested for retention, respectively. The arm pairs and $\mathrm{S}+$ arms were different among subjects. aspartic acid (NMDA; Sigma), which was dissolved in 0.1 M phosphate buffered saline (PBS; $\mathrm{pH} 7.4$ ) at a concentration of $10 \mathrm{mg} /$ mL. NMDA was injected bilaterally into each site at a rate of 0.3 injection cannula (30 gauge) connected to a $10-\mu \mathrm{L}$ Hamilton the cannula was left in place for $3 \mathrm{~min}$ at each site. . $\mathrm{LM} \pm 0.5$ (from bregma), DV -0.7 (from dura); AP -3.6 $\mathrm{LM} \pm 0.8 \mathrm{DV}-1.2 ; \mathrm{AP}-6.9, \mathrm{LM} \pm 0.9, \mathrm{DV}-1.5 ; \mathrm{AP}-8.0$ $\mathrm{LM} \pm 1.2, \mathrm{DV}-2.2$. Those for the dorsal HPC lesions were as follows: $\mathrm{AP}-2.8, \mathrm{LM} \pm 1.5, \mathrm{DV}-3.0$; $\mathrm{AP}-3.3, \mathrm{LM} \pm 2.5$, $\mathrm{DV}-3.3 ; \mathrm{AP}-3.9, \mathrm{LM} \pm 2.0, \mathrm{DV}-3.3 ; \mathrm{AP}-3.9, \mathrm{LM} \pm 3.0, \mathrm{DV}$ DV -3.5 . Cont rats received the same procedure as did rats with same volume of PBS.

After the completion of behavioral tests, the rats were deeply anesthetized with sodium pentobarbital (i.p.), and perfused intracardinally with $0.9 \%$ saline solution followed by $10 \%$ in solution for $24 \mathrm{~h}$ and then submerged in a $20 \%$ sucrose solution. Coronal sections $(40 \mu \mathrm{m})$ were cut in a cryostat (CM3000; a), and stained with cresyl violet.

Histological results are shown in Figure 2B (Experiment 1 ) (Experiment 2). Examination of the histological damage to the RS or HPC due to PBS injection. Most RS-lesioned rats sustained bilateral damage to large extents of the RS. There was no damage extended to the posterior parietal cortex. Small (he CA1 subfield of the dorsal HPC was observed in two cases in Experiment 1 and in one case in Experiment 2. Partial damage to the most caudal area of the anterior three cases in Experiment 2. Most HPC-lesioned rats had bilateral damage to the CA1-CA3 subfields of the dorsal HPC and dorsal dentate gyrus. The smallest lesioned animals in each experiment spared some bilateral CA1 subfield. None of HPClesioned rats had any damage to the RS. Partial damage to the posterior parietal cortex located dorsal to HPC occurred in three cases in Experiment 1 and in one case in Experiment 2. No substantial differences of lesion size between the two experiments were observed.

In preoperative acquisition in Experiment 1 , all subjects acquired place discrimination of the P3 and $\mathrm{P} 4$ at $4 \mathrm{wk}$ or $1 \mathrm{~d}$ before surgery. Mean number of sessions to learning criterion $( \pm$ SEM), including criterion session for $\mathrm{P} 3$ and $\mathrm{P} 4$, were $1.9 \pm 0.12$ and $1.6 \pm 0.15$, respectively. A two-way ANOVA showed that there were no significant differences among the three groups and between two pairs of training-lesion intervals (i.e., P3 and P4). Figure 2A shows mean percentage of correct responses in the retention test at each training-lesion interval. Cont rats performed well in the retention test, and the correct responses declined in accordance with the interval length. Conversely, both lesion groups showed a marked impairment at both 1 -d and 4-wk intervals. Since the reten- 


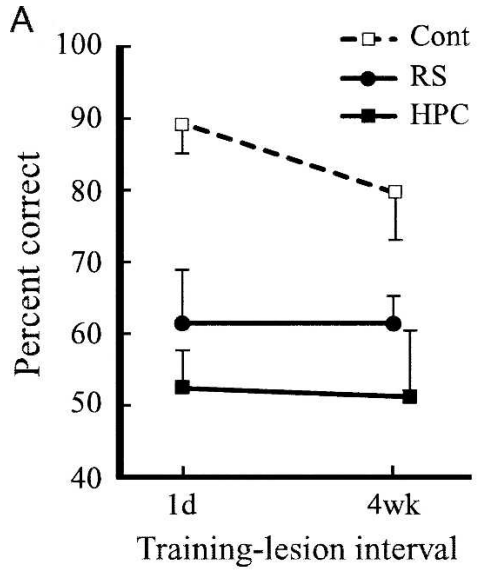

B

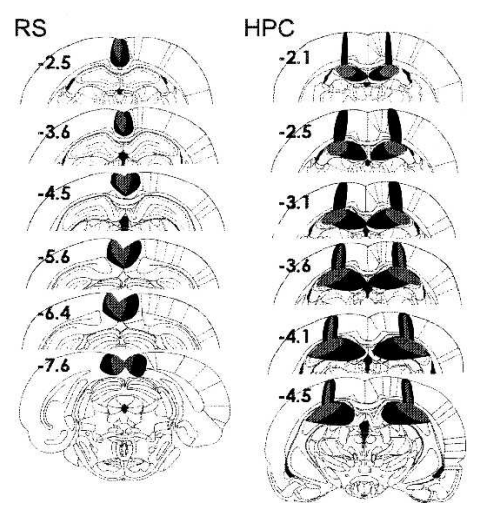

Figure 2. Behavioral and histological results of the retrograde amnesia experiment (Experiment 1). (A) Mean percent correct responses ( \pm SEM) in the retention test (12 consecutive trials). A two-way ANOVA showed a significant main effect of group $\left(F_{(2,19)}=13.84, P<0.001\right)$. Post hoc analysis by a Tukey's HSD test indicated that scores of both the RS and HPC groups were significantly lower than that of the Cont group $(P<0.05)$. Although the RS group was somewhat better than the HPC group, there was not a significant difference between two groups in both interval conditions. There were neither significant main effect of interval nor interaction between lesion $\times$ interval effects. $(B)$ Coronal brain sections illustrating the extent of the largest (black) and smallest (gray) lesions of the RS and HPC. Numbers represent the distance (in $\mathrm{mm}$ ) posterior to bregma (Paxinos and Watson 1998). Cont indicates rats with vehicle injection; RS, rats with NMDA lesion of the retrosplenial cortex; and $\mathrm{HPC}$, rats with NMDA lesion of the dorsal hippocampus.

tion performance in Figure 2A was based on all 12 trials with reinforcement, we also analyzed the animals' correct response in the first trial of the test as an accurate measure of retrograde amnesia. As shown in Table 1, the percentage of animals that showed a correct choice in the first trial of retention test almost paralleled the scores of the whole session in Figure 2A.

In preoperative place discrimination training in Experiment 2, animals acquired P1 place discrimination task in $6.4 \pm 0.3$ sessions (mean $\pm \mathrm{SEM}$ ), including the criterion session. There was not a significant difference among three groups. Figure $3 \mathrm{~A}$ shows the mean number of sessions to learning criterion of P2$\mathrm{P} 4$ in postoperative acquisition. All groups of animals could acquire P2-P4 place discrimination, and the number of sessions to criterion was smaller in all three groups than that of preoperative acquisition of P1. RS rats acquired these pairs as fast as Cont rats, while HPC animals required more sessions to criterion for each pair compared with Cont rats. Figure 3B shows mean percentage of correct responses at each retention interval in the retention test. The correct responses in the Cont and RS groups declined as the retention interval extended, and the RS rats showed a more accelerated decline. Conversely, the HPC rats' performance was at $70 \%$ irrespective of the retention interval. We also analyzed the first choice response in the retention test as in Experiment 1. Similar to the scores based on the whole retention test trials, correct responses in the RS group tended to decrease as the retention interval was prolonged, while those in the HPC group remained stable irrespective of retention intervals (Table 1). Furthermore, we analyzed if there was a significant increase of cor-
A

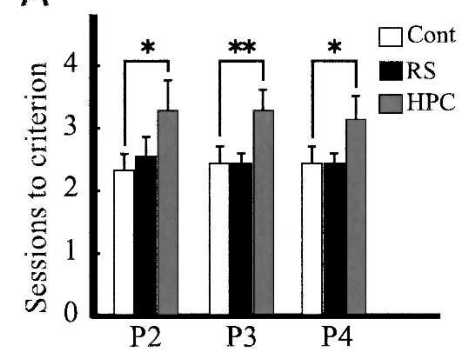

C RS

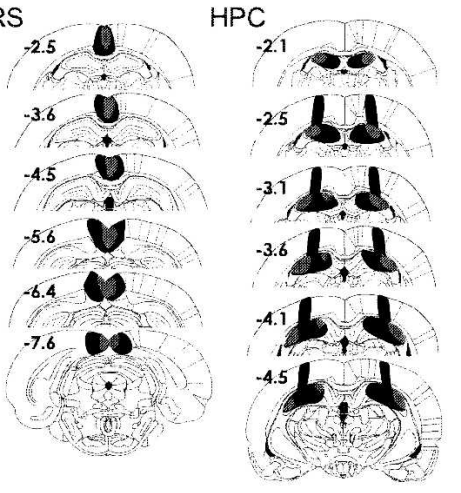

B

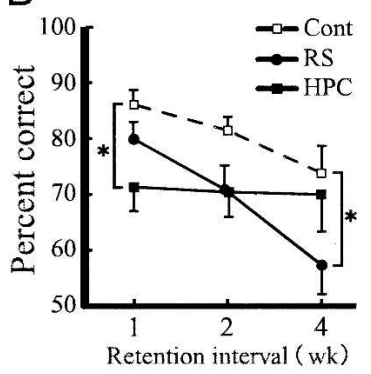

$\mathrm{D}$

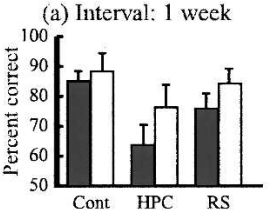

(b) Interval: 2 weeks

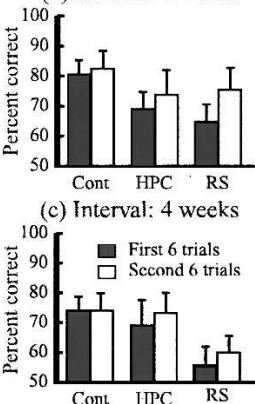

Figure 3. Behavioral and histological results of the anterograde amnesia experiment (Experiment 2). (A) Mean number of sessions to criterion ( \pm SEM) in P2-P4 acquisition. A one-way ANOVA for each arm pair showed significant main effects of group $\left(F_{(2,20)}=4.74, P<0.05\right.$ for P2; $F_{(2,20)}=7.84, P<0.01$ for P3; $F_{(2,20)}=3.92, P<0.05$ for P4). Post hoc analysis by a Tukey's HSD test in each pair revealed that the HPC group, but not the RS group, needed more sessions to criterion compared with the Cont group in all three pairs $(P<0.05$ for $\mathrm{P} 2$ and $\mathrm{P} 4 ; P<0.01$ for $\mathrm{P} 3)$. $(B)$ Mean percentage of correct responses $( \pm$ SEM) in the retention test (12 consecutive trials). A two-way ANOVA showed significant main effects of group $\left(F_{(2,20)}=3.96, P<0.05\right)$ and retention interval $\left(F_{(2,40)}=10.43, P<0.01\right)$ and a significant interaction of group $\times$ retention interval $\left(F_{(4,40)}=3.13, P<0.05\right)$. Further analyses of simple main effects at each retention interval revealed that there were significant main effects of group at 1 wk $\left(F_{(2,60)}=3.83, P<0.05\right)$ and 4 wk $\left(F_{(2,60)}=4.84, P<0.05\right)$. Post hoc comparison by a Tukey's HSD test for each retention interval indicated that the HPC animals in the 1-wk interval was lower than the Cont animals $(P<0.05)$, and the RS group in the 4-wk interval was lower than the Cont group $(P<0.05)$. (C) Coronal brain sections illustrating the extent of the largest (black) and smallest (gray) lesions of the RS and HPC. Numbers represent the distance $(\mathrm{mm})$ posterior to bregma (Paxinos and Watson 1998). (D) Mean percentage of correct responses ( \pm SEM) in the first and second halves (six trials) of the retention test. Student's $t$-test between the first and second halves showed there were no significant differences of the percentage of correct responses for all lesion groups at all retention intervals. Asterisks show significant differences from the Cont group $\left({ }^{*} P<0.05,{ }^{*} P<0.01\right)$. See also the legend for Fig. 2. 
Table 1. The number of rats in each group that chose the correct arm on the first trial of retention test

\begin{tabular}{|c|c|c|c|c|c|}
\hline \multirow[b]{2}{*}{ Group } & \multicolumn{2}{|c|}{$\begin{array}{c}\text { Experiment } 1 \\
\text { Training-lesion interval }\end{array}$} & \multicolumn{3}{|c|}{$\begin{array}{c}\text { Experiment } 2 \\
\text { Retention interval }\end{array}$} \\
\hline & $1 \mathrm{~d}$ & $4 \mathrm{wk}$ & $1 \mathrm{wk}$ & $2 \mathrm{wk}$ & $4 \mathrm{wk}$ \\
\hline & & & & & \\
\hline נה & 4 & $5 / \varepsilon$ & 6 & $5 / 8($ & \\
\hline HPC & $3 / 7(43 \%)$ & $4 / 7(57 \%)$ & $3 / 7(43 \%)$ & $5 / 7(71 \%)$ & $4 / 7(57 c$ \\
\hline
\end{tabular}

Cont indicates rats with vehicle injection; RS, rats with NMDA lesion of the retrosplenial cortex; and HPC, rats with NMDA lesion of the dorsal hippocampus.

rect choice within the session (Fig. 3D), since within-session learning could produce high levels of performance irrespective of whether animals retained information on which arm was baited. The performance of both lesion groups, as well as the Cont group, was almost the same extent in the first and second six trials at all interval conditions.

In Experiment 1, both RS and HPC groups showed a severe impairment of performance in the postoperative retention test. The correct responses of both lesion groups were very poor $(51 \%$ $61 \%$ ) irrespective of the length of the training-lesion interval. Analysis of the first trial responses in the retention test (Table 1) also showed almost the same levels of correct responses in each group, although it could not provide statistical support because of small group sizes. Thus, both lesion groups showed a severe and temporally ungraded retrograde amnesia of place discrimination. The retrograde amnesic effect of HPC lesions has been repeatedly investigated in various tasks; however, different patterns of results have been reported. Some studies showed that HPC lesions caused temporally graded retrograde amnesia (e.g., Kim et al. 1995; Clark et al. 2002), which is the phenomenon of premorbid memory loss whereby information acquired recently is more impaired than that acquired more remotely. The hypothesis based on this pattern of findings proposed that the HPC might have a time-limited role in retention and retrieval of memory until the consolidation is complete, after which memories become gradually independent of the HPC and stored in the neocortex (Squire and Alvarez 1995; Frankland and Bontempi 2005). The other studies showed that HPC lesions induced temporally ungraded retrograde amnesia (e.g., Mumby et al. 1999; Lehmann et al. 2007), in which both recent and remote memories acquired prior to injury were impaired equally. This phenomenon has led to the proposition that the HPC can contribute indefinitely to memory storage and retrieval (Nadel and Moscovitch 1997; Rosenbaum et al. 2001).

Our present results are consistent with the latter model pattern and suggest that the HPC is important for both recent and remote spatial memory. Thus, the HPC might be involved in all stages of spatial long-term memory processes that include consolidation, storage, and retrieval. Nevertheless, this does not mean that we can totally rule out the possibility that the HPC is involved in memory only for a limited period of time after learning. First, brain imaging studies using $\left[{ }^{14} \mathrm{C}\right] 2$-deoxyglucose uptake and Zif268 expression technique have shown that remote spatial memory could become independent of HPC with the passage of time (Bontempi et al. 1999; Maviel et al. 2004; Frankland and Bontempi 2005). Second, most of the previous studies using spatial memory tasks reported temporally ungraded retrograde amnesia after HPC lesions (e.g., Bolhuis et al. 1994; Martin et al. 2005), while in nonspatial memory tasks such as social transmission of food preference (Clark et al. 2002) HPC-lesioned rats showed temporally graded retrograde amnesia. We hypothesize that the HPC plays an important role not only in spatial memory but also in on-line spatial information processing ( $\mathrm{O}^{\prime}$ Keefe and Nadel 1978; Poucet et al. 2003). Since spatial memory tasks require on-line spatial information processing as well as spatial memory, HPC lesions could disturb the task performance even after a limited period of time and thus produced temporally ungraded retrograde amnesia. Based on this view, one may or may not observe a temporally graded retrograde amnesia depending on the details of the test situation. Taken together, temporally ungraded retrograde amnesia obtained in the present study suggests the long-lasting HPC contribution to memory formation. However, another possibility could be that the deficient spatial processing by HPC lesions during the retention test caused a low level of retention test performance.

Concerning the function of the RS, we have found evidence for temporally ungraded retrograde amnesia induced by the lesion of this area for the first time. The result suggests the possibility that the RS is needed indefinitely for spatial long-term memory. However, increased Zif268 expression in the RS has a been reported if animals were tested $30 \mathrm{~d}$, but not at $1 \mathrm{~d}$, after training in a five-arm radial maze as a reference memory task (Maviel et al. 2004), and this pattern of expression was in contrast to the expression in the HPC. Thus, it seems that the RS has a time-limited role in spatial memory and is important for remote memory, but not for recent memory. On the other hand, the RS contains cells with strong spatial correlation (Chen et al. 1994; Cho and Sharp 2001), and this suggests that the RS is necessary for on-line spatial information processing to perform spatial tasks as well as the HPC; the present results could be due to the deficit of spatial processing itself during the retention test as well as the deficit of spatial memory. Taken together, our present results suggest that the RS might contribute to both recent and remote memories acquired prior to lesions. However, further investigation is needed to determine whether the same kind of results would be obtained even if nonspatial tasks were tested.

In Experiment 2, clearly different patterns of anterograde amnesia between the RS and HPC groups were observed. In postoperative place discrimination training, all three groups could acquire P2-P4 and needed fewer sessions to acquire them than to acquire P1 in preoperative training. This suggests that all groups of animals could retain the presurgically acquired memory of how to solve the problem in the apparatus. However, only HPClesioned rats took significantly more sessions to criterion than the Cont group. This is consistent with a previous study in which HPC-lesioned rats were impaired to learn place discrimination of a new arm pair (Cho et al. 1995). In order to acquire place discrimination in the present study, subjects might have been required to maintain information on which arm was baited during training. Therefore, the HPC rats might have a difficulty in maintaining this information even for a limited, short period of training session (up to 10-20 min). Conversely, the RS group could acquire P2-P4 as fast as the Cont group. Previous studies reported that RS-lesioned rats that had preoperative training showed mild impairment compared with those without preoperative training (Lukoyanov et al. 2005; Cain et al. 2006). Thus, since in the present experiment we conducted preoperative training using different alternatives, RS-lesioned rats might have been able to perform normally in postoperative place discrimination training.

In retention tests of postoperatively acquired discrimination (Fig. 3B; Table 1), correct performance of the Cont animals showed a gradual decrease as the retention interval increased. The RS group showed a remarkable retention interval-dependent impairment. It must be noticed that the RS-lesioned rats completely failed to discriminate the adjacent two arms that they learned $4 \mathrm{wk}$ before, although they could discriminate other adjacent two arms almost to the same extent as the Cont animals if they learned it $1 \mathrm{wk}$ before. This pattern of impairment strongly 
suggests that the role of the RS in spatial memory required for this task changes depending on the time after acquisition. Our present results might reflect a deficit of long-term storage and/or retrieval after long-term storage, since performance of the RS animals was impaired only with a long retention interval. This may be consistent with the finding that the expression of Zif268 was elevated in the RS after the test of remote spatial memory, but not of recent memory (Maviel et al. 2004). The RS is proposed as a candidate brain region that forms a network with hippocampal formation in memory function, since the RS has dense neural connections with hippocampal formation. Consistent with this view, our result suggests that the RS may contribute to a more permanent store of the information in the cortical area.

Conversely, HPC-lesioned rats performed the task at the same level regardless of the retention interval. Accordingly, correct performance level of the HPC group was inferior to that of the Cont group when tested $1 \mathrm{wk}$ after training, while it was almost the same as the Cont group when tested 4 wk after training. This result suggests that the HPC might have a more important role for recent memory rather than for remote memory. In addition, the performance of the HPC group in the retention test was clearly different from that of the RS group. This might reflect the functional difference between the RS and HPC in spatial long-term memory and suggests the possibility that the relative importance of RS and HPC function had changed as time passed. However, it should be considered that the performance of the HPC group did not show any gradient as the retention interval increased, and it was $\sim 70 \%$ correct level, but not $50 \%$ level, even in the shortest retention interval. It should be noticed that HPClesioned rats could acquire the discrimination of all three arm pairs without intact dorsal HPC function. Although the learning was slower than the Cont animals, HPC-lesioned animals could acquire the task, suggesting that other brain regions, including residual HPC areas, might have compensated for the lesioned dorsal HPC. One may suppose that within-session learning in the retention test could produce performance above chance level and a flat gradient amnesia. However, the significant increase of correct performance within the session was not observed in all retention intervals (Fig. 3D). Thus, this possibility could not explain results of the HPC group in the present study. The reason why the HPC group could maintain 70\% level performance at all intervals despite the loss of sufficient HPC function is not clear at present. However, our view that residual HPC or other brain regions might have compensated for the HPC function may partly explain these results. In order to solve this problem, further study employing additional lesion groups will be needed.

\section{Acknowledgments}

This work was supported by the 21st Century COE Program from the MEXT of Japan, and by JSPS (15330153).

\section{References}

Albasser, M.M., Poirier, G.L., Warburton, E.C., and Aggleton, J.P. 2007. Hippocampal lesions halve immediate-early gene protein counts in retrosplenial cortex: Distal dysfunctions in a spatial memory system. Eur. J. Neurosci. 26: 1254-1266.

Bolhuis, J.J., Stewart, C.A., and Forrest, E.M. 1994. Retrograde amnesia and memory reactivation in rats with ibotenate lesions to the hippocampus and subiculum. Q. J. Exp. Psychol. 47B: 129-150.

Bontempi, B., Laurent-Demir, C., Destrade, C., and Jaffard, R. 1999. Time-dependent reorganization of brain circuitry underlying long-term memory storage. Nature 400: 671-675.

Burwell, R.D. and Amaral, D.G. 1998. Cortical afferents of the perirhinal, postrhinal, and entorhinal cortices of the rat. J. Comp. Neurol. 398: 179-205.

Cain, D.P., Humpartzoomian, R., and Boon, F. 2006. Retrosplenial cortex lesions impair water maze strategies learning or spatial place learning depending on prior experience of the rat. Behav. Brain Res.
170: $316-325$

Chen, L.L., Lin, L.H., Green, E.J., Barnes, C.A., and McNaughton, B.L. 1994. Head-direction cells in the rat posterior cortex. I. Anatomical distribution and behavioral modulation. Exp. Brain Res. 101: 8-23.

Cho, J. and Sharp, P.E. 2001. Head direction, place and movement correlates for cells in the rat retrosplenial cortex. Behav. Neurosci. 115: 3-25.

Cho, Y.H., Kesner, R.P., and Brodale, S. 1995. Retrograde and anterograde amnesia for spatial discrimination in rats: Role of hippocampus, entorhinal cortex, and parietal cortex. Psychobiology 23: $185-194$.

Clark, R.E., Broadbent, N.J., Zola-Morgan, S., and Squire, L.R. 2002. Anterograde amnesia and temporally-graded retrograde amnesia for a nonspatial memory task following lesions of hippocampus and subiculum. J. Neurosci. 22: 4663-4669.

Cooper, B.G. and Mizumori, S.J.Y. 2001. Temporary inactivation of the retrosplenial cortex causes a transient reorganization of spatial coding in the hippocampus. J. Neurosci. 21: 3986-4001.

Destrade, C. and Ott, T. 1982. Is a retrosplenial (cingulate) pathway involved in the mediation of high frequency hippocampal rhythmical slow activity (theta)? Brain Res. 252: 29-37.

Eichenbaum, H., Otto, T., and Cohen, N.J. 1994. Two functional components of the hippocampal memory system. Behav. Brain Sci. 17: 449-518.

Frankland, P.W. and Bontempi, B. 2005. The organization of recent and remote memories. Nat. Rev. Neurosci. 6: 119-130.

Kim, J.J., Clark, R.E., and Thompson, R.F. 1995. Hippocampectomy impairs the memory of recently, but not remotely, acquired trace eyeblink conditioned responses. Behav. Neurosci. 109: 195-203.

Lehmann, H., Lacanilao, S., and Sutherland, R.J. 2007. Complete or partial hippocampal damage produces equivalent retrograde amnesia for remote contextual fear memories. Eur. J. Neurosci. 25: 1278-1286.

Lukoyanov, N.V., Lukoyanova, E.A., Andrade, J.P., and Paula-Barbosa, M.M. 2005. Impaired water maze navigation of Wistar rats with retrosplenial cortex lesions: Effect of nonspatial pretraining. Behav. Brain Res. 158: 175-182.

Maguire, E.A. 2001. The retrosplenial contribution to human navigation: A review of lesion and neuroimaging findings. Scand. J. Psychol. 42: 225-238.

Martin, S.J., de Hoz, L., and Morris, R.G.M. 2005. Retrograde amnesia: Neither partial nor complete hippocampal lesions in rats result in preferential sparing of remote spatial memory, even after reminding. Neuropsychologia 43: 609-624.

Maviel, T., Durkin, T.P., Menzaghi, F., and Bontempi, B. 2004. Sites of neocortical reorganization critical for remote spatial memory. Science 305: 96-99.

Mumby, D.G., Astur, R.S., Wiesend, M.P., and Sutherland, R.J. 1999. Retrograde amnesia and selective damage to the hippocampal formation: Memory for places and object discriminations. Behav. Brain Res. 106: 97-107.

Nadel, L. and Moscovitch, M. 1997. Memory consolidation, retrograde amnesia and the hippocampal complex. Curr. Opin. Neurobiol. 7: 217-227.

O'Keefe, J. and Nadel, L. 1978. The hippocampus as a cognitive map. Clarendon, Oxford.

Pan, W.-X. and McNaughton, N. 1997. The medial supramammillary nucleus, spatial learning and the frequency of hippocampal theta activity. Brain Res. 764: 101-108.

Paxinos, G. and Watson, C. 1998. The rat brain in stereotaxic coordinates, 4th ed. Academic Press, San Diego, CA.

Pothuizen, H.H., Zhang, W.N., Jongen-Rêlo, A.L., Feldon, J., and Yee, B.K. 2004. Dissociation of function between the dorsal and the ventral hippocampus in spatial learning abilities of the rat: A within-subject, within-task comparison of reference and working spatial memory. Eur. J. Neurosci. 19: 705-712.

Poucet, B., Lenck-Santini, P.P., Paz-Villagran, V., and Save, E. 2003. Place cells, neocortex and spatial navigation: A short review. J. Physiol. 97: 537-546.

Rosenbaum, R.S., Winocur, G., and Moscovitch, M. 2001. New views on old memories: Re-evaluating the role of the hippocampal complex. Behav. Brain Res. 127: 183-197.

Squire, L.R. 1992. Memory and the hippocampus: A synthesis from findings with rats, monkeys, and humans. Psychol. Rev. 99: 195-231.

Squire, L.R. and Alvarez, P. 1995. Retrograde amnesia and memory consolidation: A neurobiological perspective. Curr. Opin. Neurobiol. 5: $169-177$.

Sutherland, R.J., Whishaw, I.Q., and Kolb, B. 1988. Contributions of cingulate cortex to two forms of spatial learning and memory. $J$. Neurosci. 8: 1863-1872.

Valenstein, E., Bowers, D., Verfaellie, M., Heilman, K.M., Day, A., and Watson, R.T. 1987. Retrosplenial amnesia. Brain 110: 1631-1646.

Vanderwolf, C.H., Leung, L.-W.S., and Cooley, R.K. 1985. Pathways 
through cingulate, neo- and entorhinal cortices mediate atropine-resistant hippocampal rhythmical slow activity. Brain Res. 347: $58-73$.

Vann, S.D. and Aggleton, J.P. 2002. Extensive cytotoxic lesions of the rat retrosplenial cortex reveal consistent deficits on tasks that tax allocentric spatial memory. Behav. Neurosci. 116: 85-94.

Vann, S.D. and Aggleton, J.P. 2004. Testing the importance of the retrosplenial guidance system: Effects of different sized retrosplenial cortex lesions on heading direction and spatial working memory. Behav. Brain Res. 155: $97-108$

Vann, S.D., Brown, M.W., Erichsen, J.T., and Aggleton, J.P. 2000. Using fos imaging in the rat to reveal the anatomical extent of the disruptive effects of fornix lesions. J. Neurosci. 20: 8144-8152.

Vogt, B.A. 1986. Cingulate cortex. In Cerebral cortex (eds. A. Peters and E.G. Jones), pp. 89-149. Plenum Press, New York.

Wyss, J.M. and van Goren, T. 1992. Connections between the retrosplenial cortex and the hippocampal formation in the rat: A review. Hippocampus 2: 1-12.

Received November 30, 2007; accepted in revised form April 24, 2008. 


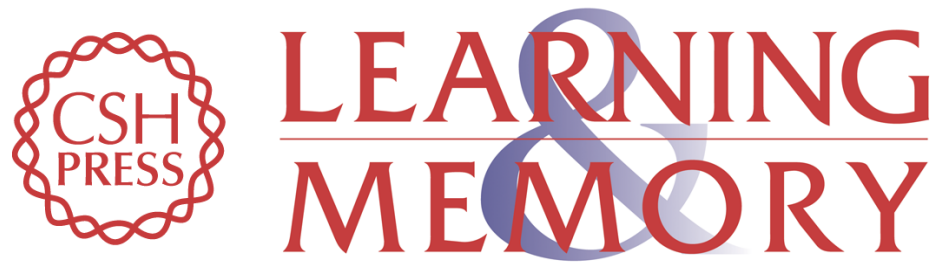

\section{Anterograde and retrograde amnesia of place discrimination in retrosplenial cortex and hippocampal lesioned rats}

Asahi Haijima and Yukio Ichitani

Learn. Mem. 2008, 15:

Access the most recent version at doi:10.1101//m.862308

References This article cites 34 articles, 5 of which can be accessed free at:

http://learnmem.cshlp.org/content/15/7/477.full.html\#ref-list-1

License

Email Alerting Receive free email alerts when new articles cite this article - sign up in the box at the Service top right corner of the article or click here. 